\title{
Psychopathy in Serial Killers and Political Crime
}

\author{
Vito Zepinic \\ PsychClinic P/L, London, UK \\ Email: vito@psychclinic.net
}

How to cite this paper: Zepinic, V. (2018). Psychopathy in Serial Killers and Political Crime. Psychology, 9, 1262-1283.

https://doi.org/10.4236/psych.2018.96077

Received: April 20, 2018

Accepted: June 19, 2018

Published: June 22, 2018

Copyright $\odot 2018$ by author and Scientific Research Publishing Inc. This work is licensed under the Creative Commons Attribution International License (CC BY 4.0).

http://creativecommons.org/licenses/by/4.0/

\begin{abstract}
Serial killers or mass-murders had always been subject of interest for the science (criminology, sociology, psychiatry, psychology, etc.), as well as those individuals in power responsible for the crimes against humanity. Such psychopaths usually receive enormous attention by the media, but also by a public in general. Relation between psychopathy and crime is a quite controversial-not every psychopath is a criminal; neither every criminal is a psychopath. This may sound a discouraging preamble in the study of psychopathy and crimes. Even more discouraging to the forensic psychiatrists and psychologists is the fact that the most courts view psychopathy with a profound suspicion, regarding it often as a piece of the psychiatric flummery designed to frustrate their prerogative of sentencing confirmed offenders.
\end{abstract}

\section{Keywords}

Psychopathy, Insanity, Serial Killer, Political Crime, Terrorism

\section{Diagnostic Dilemma}

A clinically useful and empirically sound classification of personality disorders has been a persistent problem in psychiatry and psychology. A clinically useful diagnostic system should encompass the spectrum of personality psychopathology seen in clinical practice indicating it is a syndromal, not a simple disorder. Clinicians and researchers are coming to a consensus about a range of problems in personality disorder-a patient diagnosed with any personality disorder receives multifaceted diagnostic comorbidity and has often been summarised as psychopath. Because of the multifaceted syndromes encompassing one's cognition, affectivity, motivation, interpersonal functioning, attachment, and so on, term "psychopathy" avoids the narrowed DSM criterion sets and simple personality traits (single dimensions) of a specific personality disorder. 
However, psychopathy is without any question, the most interesting and, at the same time, one of the most baffling problems in clinical psychology and psychiatry (Zepinic, 2018). In the first place, a substantial number of the clinicians do not believe there is any such condition and those who even somehow reluctantly recognised its existence, nevertheless regard the psychopathy as a dumping ground for an unspecified syndromal disorder of the personality. Indeed, one of the distinguishing features of the psychopathy, as an unclassified mental disorder, is that the psychopath is a dysfunctional person. However, as many psychopaths give a superficial impression not only of "normality" but of an extremely frank, plausible and, at times, charming disposition, it is not at all surprising that both the courts and the commonality regard with a suspicion any attempt of the "experts" to find extenuating circumstances for one's psychopathic conducts (Glover, 1960).

Unfortunately, the diagnostic situation did not change much with introduction of DSM or ICD classification of the mental disorders as, for example in the DSM-5 (APA, 2013), psychopathy is not included as a separate disorder of personality. Thus, in practice, the clinicians are left to consider psychopathy as the syndromal condition of the personality disorders (antisocial, borderline, narcissistic), often combined with the psychotic features of other disorders (Zepinic, 2018).

Differential diagnosis of psychopathy is difficult enough mainly due to three facts, first, that the clinical diagnosis reflects the current state of a psychiatric opinion; second, that psychiatric classifications of mental disorder are so far of the most rudimentary order, and third that, in practice, the forensic psychiatrists and psychologists are concerned mainly with grave mental disorders and have little interest in character disorders, and less in those character disorders that are responsible for the criminal behaviour ("moral Insanity"). Further controversies exist in regard to whether the psychopathy is the condition because of constitutional or psychological factors ("guilty mind or guilty brain"), and also is that condition conscious or unconscious of its origin (Zepinic, 2018).

In general, based on their behaviour, affects, and relatedness, we can classify psychopaths within three dominant groups: 1) aggressive: person who attempt to injury themselves or others, alcoholics or drug addicts, and sexual offenders; 2) inadequate: those who mainly related to the crimes, lying or swindling and more persistently abnormal than aggressive type and leaning towards psychosis, but regarded as charming companions; and 3) creative: those geniuses who manifest mental states of unbalance, heightened sensitivity and ability or "talent", and disordered psychic equilibrium (instability, queerness, explosiveness, intuitiveness, and egocentricity). It should be pointed out that, in order to obtain an accurate picture of the "criminal psychopath", the main picture is estimated by social rather than the clinical consideration.

On the other hand, it cannot be denied that the antisocial (asocial) psychopath, despite his apparent lack of social conscience, may nevertheless have a sys- 
tem of private values which does not differ greatly from the normal persons. Moreover, the "normal-but-psychopath" persons (politicians, corporate managers, lawyers, doctors, law enforcement officials, etc.) may be found to have a number of antisocial traits which, however, do not bring them in open conflict with the law (Cleckley, 1982; Hare, 1970; Zepinic, 2018). In other words, the psychopathy is in the clinical sense a cluster-formation, a syndrome comprising variety of elements of disordered personality and, while defining psychopathy, we must establish whether the combination of the elements is specific enough to justify a special group designation (criminal or non-criminal psychopath), and second, to see whether sub-divisions can be effected in accordance with the loading of different elements (Zepinic, 2018). The elements of the syndrome condition should not be too grossly antithetical in function.

Clinical practice aimed at refining psychopathy is often constrained by the use of the assessment instruments designed to assess the existing DSM categories and criteria. Such assessment instruments implicitly presume the basic accuracy to evaluate one specific personality disorder as a simple not a syndromal phenomenon and, therefore, can lead to omit the multifaceted traits. This paper attempts to identify the central features of the psychopathy as the syndromal condition as it is 1) conceptualised by practicing clinicians, and 2) observed empirically in psychopathic patients treated. In this paper, psychopathy is observed as a composite syndrome of Cluster B Personality Disorders described in DSM-5. This composite description includes items absent from the DSM-5 criterion sets such as addressing externalisation of blame, lack of empathy, lack of remorse, an imperviousness to consequences, sadism, and a tendency to manipulate others' emotions.

\section{Are the Serial Killers "Semi-Successful" Psychopaths?}

For the past two decades, we have witnessed quite significant increase in research of psychopathy, either in regards to the criminal behaviours or those who live relatively successful lives. In general, the psychopath is considered as an individual who manifests the core psychopathic features of the affective and interpersonal deviances, but some manage to stay out of the criminal justice system. These circumstances often result in a contradictory approach towards psychopathy in the proposition to explain how successful psychopath differs from the normal population.

Further, in clinical and legal practice, the serial killers usually have a history as "normal" individuals whose behaviour could not indicate any hidden psychopathic traits until they committed horrible crime. Four features are noteworthy in serial killer psychopath. First, clinicians have clear conceptions of antisocial and narcissistic personality even recognising that serial killer's psychopathy shares common features (e.g., lack of empathy, a tendency to externalise blame, a power-oriented approach to others, problems with hostility). These features have usually been hidden for a long period of time living unresolved puzzles for 
law and psychiatry what was particular reason that "normal" individual suddenly become a serial killer.

Second, the clinicians' consensual understanding of the antisocial personality disorder encompasses many features of the construct of psychopathy that preceded the current antisocial personality disorder diagnosis (Cleckley, 1982). Clinicians emphasised lack of concern with the fact what has happened, lack of empathy and remorse, callous lack of concern for others, incapacity to experience guilt, and interpersonal manipulativeness by serial killer as a "normal" individual. However, these aspects of mental life are absent from the DSM- 5 criterion sets, which instead emphasises behavioural markers such as criminality and lack of stable employment.

Third, clinicians do not have well-differentiated conceptions of borderline and histrionic personality disorder which the personality traits and pathological features (tendency to become attached quickly and intensely, emotions that spiral out of control, difficulty regulating emotion without the involvement of another person, impulsivity) are also quite common in serial killer psychopath. Further, it is common that personal history of serial killer includes the evidences of unstable, chaotic, and rapidly changing his interpersonal relationships, lacks a stable image of who is he or would like to become (e.g., attitudes, values, goals, and feelings about self), tends to fear he will be rejected or abandoned by those who are emotionally significant, tends to express intense and/or inappropriate anger, out of proportion to the situation at hand, express emotions in exaggerated and theatrical ways, seeks to be the centre of attention, tends to be suggestible and/or easily influenced.

Forth, the serial killer's psychopathy reveals a coherent syndrome that strongly resembles the DSM-5 description of narcissistic personality disorder. The serial killers have a history of an exaggerated sense of self-importance, have little empathy and unable to understand or respond to others' needs and feelings unless they coincide with the psychopath's own, treat others primarily as an audience to witness own importance, brilliance, etc. Further, they tend to believe they can only be appreciated by, or should only associate with, people who are high-status, superior, or otherwise "special".

Gao \& Raine (2010) postulated that one's intact or enhanced neurobiological processes, including better executive functioning, increased autonomic reactivity, normative volumes of prefrontal grey area and amygdale, and normal frontal functioning, may serve as factors that protect successful psychopaths from a conviction and allow them to attain their life goals, using more covert and non-violent approach. In contrast, brain structural and functional deficit, alongside with the reduced automatic reactivity, an impaired executive functioning, and risky decision making, predispose unsuccessful psychopaths to a more extreme form of the antisocial behaviours utilising more overt and aggressive methods of manipulation.

Hare (1970) has defined the psychopath as an individual having personality 
that includes glibness, manipulation, callousness and lack of emotion (emotionless), irresponsibility, impulsivity, and aggression. It is generally agreed that the lack of emotion and remorse are the core characteristics of the psychopathy, with the most debatable issues being whether criminal behaviour is a necessary feature of the psychopathy and whether the affective-emotional impairments should be considered within the diagnostic criteria of psychopathy. At the same time, many theorists, (Blair, 2006; Cleckley, 1982; DeLisi, 2009; Hare, 1970; Patrick, 2006; Walters, 2004) have been of opinion that the cognitive and affective-emotional processing deficits associated with the brain abnormalities, particularly structural and functional impairments in the amygdale and the orbitofrontal and ventromedial prefrontal cortex, are the most commonly found organic abnormalities in the psychopathic individuals.

Furthermore, the evidences from the psychophysiological, neurological, brain imaging, neuroendocrinal, and neuropsychological research also suggest that psychopathy may in part be neurodevelopmentally determined. For example, atypical amygdale activation in response to emotional stimuli, neurobiological deficits including lower cortical levels, and reduced electrodermal stress response are found in adult psychopaths but also in children and adolescent with psychopathic tendencies. Taken together, the evidence of early neurodevelopmental abnormalities may indicate an early detection of psychopathic personality.

In his influential book, Mask of Sanity, Cleckley (1982) documented a high functioning of the successful psychopaths, including businessmen, physicians, and scientists, who have been characterised by traits of the ego-centricity, superficial charm, and irresponsibility but no event of their criminal charges nor convictions. He was of opinion that the successful psychopaths represent "incomplete" manifestations or suggestions of the disorder, and he explicitly emphasised that the psychopathy is a dysfunctional personality style that is prevented in the general population. For example, in the case of the physician that the Cleckley (1982) presented in his book, the successful psychopath has been described as being manipulative, conning, charming, lacking emotions, and engaging in promiscuous sexual behaviour, but was able to be successful in maintaining high social status as respected physician.

The prevalence of psychopathy is not definitely known, but it is estimated that 3.5 per cent are present in the business world (Babiak \& Hare, 2006). In a study conducted by Raine \& colleagues (2004), the Psychopathic Checklist-Revised $(P C L-R)$ was used to assess psychopathy and successful psychopaths; successful psychopaths were defined as those who scored high on the $P C L-R$ but who had never been convicted for any crime, or based on official criminal records. Compared with unsuccessful psychopaths who had at least one conviction, the increased heart rate stress reactivity and enhanced executive functioning were found in successful psychopaths. Successful psychopaths also shown better executive functioning than the non-psychopathic control group. 
On the other hand, unsuccessful psychopaths have exhibited reduced heart rate stress reactivity and impaired executive functioning compared with non-psychopathic controls, as observed in the criminal psychopaths. Two psychopathic groups did not differ on the full scale of the IQ compared with non-psychotic controls. It was argued that enhanced autonomic responding and better executive functioning might protect the successful psychopaths from being detected and arrested, allowing them to perpetrate significant harm to others, but avoiding punishment.

Raine et al. (2004) reported an exaggerated anterior hippocampal volume asymmetry (right $>$ left) in unsuccessful psychopaths, but not with the successful psychopaths or non-psychopathic controls, suggesting an importance of the neurodevelopmental basis in the unsuccessful psychopaths. Similarly, significant grey matter volume reduction in the prefrontal cortex and the amygdala has also been found in the unsuccessful, but not in successful psychopaths. Within the prefrontal cortex, structural impairments found in unsuccessful psychopaths are specific to the orbitofrontal cortex and middle frontal gyrus.

Iria \& Barbosa (2009) examined fear facial expression recognition ability among criminal and non-criminal psychopaths. The non-criminals and non-psychopaths were recruited from local employment centres, and psychopathic and non-psychopathic criminals were recruited from prisons and police stations. Compared with non-psychopaths, psychopaths performed significantly worse on detecting and discriminating the facial expression of fear; criminal and non-criminal psychopaths did not differ on this task. Their findings implicate the cognitive deficits common in both groups: successful and unsuccessful psychopaths; although one limitation is that the authors did not control for the duration of incarceration, alcohol use, and drugs use-factors that may confound the association between psychopathy and facial expression recognition ability.

The authors of the research found that successful and unsuccessful psychopaths share some similarities in terms of a fear expression recognition deficits; factors that may explain why both successful and unsuccessful groups are psychopathic. At the same time, the differences between successful and unsuccessful psychopaths were also apparent. It was suggested that the neuropathological characteristics, including reduced prefrontal grey matter and amygdala volumes and abnormal hippocampal asymmetry, may contribute to the cognitive and emotional dysregulations in unsuccessful psychopaths and consequently render these individuals less sensitive to the environmental cues predicting danger and capture.

On the other hand, enhanced frontal functioning and better executive capability may protect successful psychopaths from being detected and convicted of the crime. If successful psychopaths are defined as individuals with psychopathic characteristics but who also somehow successfully have avoided of being charged or arrested, then the question is whether the psychopathic serial killers who have escaped detection for a significant period after intense police scrutiny 
potentially give clues on the aetiology of successful psychopaths?

A serial killer is commonly understood to be a person who murders three or more persons over a period of more than thirty days, with a "cooling off" period between each murder, and whose motivation for the killings is based largely on sexual gratification or internal psychological gratification (Kreamer et al., 2002). Kreamer et al. (2002) found that serial killers are deliberate and premeditating, and they lack of the interpersonal conflicts and provocations more frequently seen in single homicide offenders. Kreamer et al. (2002) further found that the crime scenes are more organised, and the serial killers exhibited superior planning by moving the victim or body from one location to another, by using restraints, and by disposing of the body in remote locations.

Serial murders and psychopathy are inevitable linked, although it is not necessary that the serial killers display the characteristic traits of superficial charm, intelligence, lack of remorse, impulsivity, and associated psychopathic traits. The fact that psychopathic serial killers can carefully plan and perpetrate their criminal acts without being detected for, sometimes, considerable periods of time (even despite an intense search by the police), combined with their cruel and sadistic acts with no empathy or remorse for the victims, suggests the hypothesis that they constitute a form of "semi-successful" psychopaths (Zepinic, 2018; Gao \& Raine, 2010).

Psychopathic serial killer can identify vulnerable and passive (powerless) victims, including females, children, and elderly seniors. They usually use their superficial charm and glibness to win their affection by the victims pretending to be compassionate, loving, carers, and considerable. With their capacity, they can relocate victims from one place to another, making investigation more complex and, at the same time, making it less possible to detect them as the killers. Jenkins (1960) found that, unlike the single murderer, many serial killers were married with a stable family life, and they have often been valuable members of the community.

Serial killers may be capable of engaging in a very serious violence without being caught for sustained periods because they possess the adaptive features (e.g., good executive functioning, efficient information-processing, adaptive stress reactivity) that are similar to those with the successful psychopath (Gao \& Raine, 2010). This creates confusion and uncertainty among the court experts, usually psychiatrists and psychologists, about two highly visible forensic psychiatric examinations: the psychopath's competence to stand a trial, and the criminal (ir)responsibility (insanity or diminished responsibility).

One of the quite conflicting cases regarding psychiatric examination and unusual clash of interest was the case of Breivik, who murdered seventy-seven people in Norway in July 2011. With conflicting psychiatric reports regarding his (in)sanity, prosecutors argued that Breivik should be found not guilty by reason of insanity, whereas the defence (and Breivik himself) strongly maintained that he was sane and responsible for his action. Imposing an insanity defence on an 
unwilling accused pits the societal interest in fair adjudication against the right of the accused to control his defence. For crimes with "political" motivations, an imposed insanity verdict discredits the perpetrator and may distract the public from the threats posed by extreme political views (Appelbaum, 2013).

During his killing rampage, Anders Behring Breivik left 77 people dead. The first attack occurred in a cluster of the government buildings in Oslo, Norway, where he set off a car bomb made from fertilizer and fuel oil that killed eight people. Then he drove to a nearby lake, taking a ferry to Utoya Island, where a summer camp meeting was held of the youth country's ruling Labour Party. Dressed as a policeman and heavily armed he then killed 69 and wounded 66 others. When police arrived, he surrendered without a struggle.

At his trial, Breivik readily admitted killings but argued that this action "was the most spectacular sophisticated political act in Europe since the World War II" and that he would do it again. He stated that his action was a "self-defence" to protect Norway from the growing influence of Muslim ${ }^{1}$ immigrants and multiculturalism.

Breivik was a 32-year-old person with a reasonably privileged and conventional background-his father was a diplomat and mother a nurse. He considers his act as the "political correctness" and, just before his crimes, he had posted on the Internet a bizarre, rambling but coherent 1500-page political manifesto entitled "2008: A European Declaration of Independence", which contains his ideological and populist rants. His massacre on Utoya Island he declared was no less than a war in defence of Western civilisation on behalf of a group he called the Knights Templar. He claimed that he travelled to the UK where the group had reactivated the medieval order of knights to fight the modern scourge, the conspiracy of the Muslims and their treacherous allies. Breivik claimed he had been ordinated as the $8^{\text {th }}$ justiciar knight for the Knights Templar Europe. It was this name that he used to sign off his diary entry before carrying out his attacks.

The first real clues about Breivik's psychopathy background emerged in the passage of his manifesto concerning feminism. In his opinion, it is a central, modern evil, and European women had been ruined by it as they no longer had enough children to keep the threat from the faster breading Muslims at bay. To this end, he proposed that Christian women should be discouraged from having anything above a bachelor's degree and face three options: "be a nun, be a prostitute, or marry man and bear children". The most vindictive chapters aimed at his mother and sister-he railed against them both as "promiscuous" and representatives of the degraded and degenerate modern humanity. He condemned his half-sister for contracting chlamydia "after having more than forty sexual partners" and claimed that his mother had multiple sexual partners before develop-

${ }^{1}$ None of killed nor injured was a Muslim—all of them were Norwegians. 
ing meningitis from venereal disease.

Further in his manifesto, Breivik stated that he did not approve of his super-liberal, matriarchal upbringing, as it completely lacked discipline and his father-absent childhood contributed to feminise him to a certain degree. Perhaps this fear of being feminised can account for Breivik's hyper-masculine photos at the end of his manifesto. He smiles and poses in profile shots, wearing a self-designed Knights Templar or military uniform with medals and posted photos on the Facebook.

After his arrest, the Breivik's mental state was examined by two psychiatrists, who reached opposite conclusions about his mental state at the time of the crime: one report described him as psychotic due to paranoid schizophrenia, whereas a second evaluation concluded that he had not been psychotic but did have narcissistic personality disorder. In general, there was no question about admitted actus reus, but the evaluation of his mens rea has been in dispute. Although in criminal proceeding the insanity defence is taken under one percent, the Breivik's trail presented an unusual spectacle, as the accused insisted he was sane during killings while the prosecution argued for a finding defence on insanity. In essence, the prosecution was attempting to have an insanity verdict imposed over the objections of the accused, in regard to the conflicting reports about his mental state. This unusual turn of the defence, which usually decides the trail strategy imposing the insanity defence, arguing that the accused has been sane and willing to commit a crime, was out of defence's basic notions of pleadings.

The diagnosis of the Breivik's paranoid schizophrenia has been opposed by some leading psychiatrists and psychologists, who argued that his high-functioning was not consistent with schizophrenia. He was able to plan and execute the bombing and mass murder, and his 1500-page manifesto showed a real ability for good mental organisation and orders. The manifesto shows intelligence, a capacity for marshalling evidence, and sophisticated cognitive skills. There was no evidence exhibited of the "world salad" typical to the schizophrenia-odd pairings and parsing of words and phrases that are connected by associations known only to the sufferer, rather than by logic.

From clinical experience, the executive function in people who are suffering from schizophrenia, in acute and confronted situations with significant organisational demands, is often disintegrative. However, Breivik's capacity to execute very complex and highly coordinated plan remained intact. He had no visual or the auditory hallucinations; nor did show the ambulatory restlessness or elevated mood common to an acute phase of the schizophrenia.

A psychiatrist who treated Breivik in prison during trail stated that the accused was not in a psychotic state. Dr Rosenquist, a forensic psychiatrist who examined Breivik, was of the opinion that diagnosis of paranoid schizophrenia was a political decision. There was a much better diagnosed disorder - personality psychopathic disorder with a malignant narcissism-perhaps one of the most 
extreme ever seen. One of the leading aspects of this disorder has been Breivik's lack of empathy, in addition to grandiosity, obsession with personal appearance, his willingness to exploit others for his own needs, the sense of entitlement, absence of the fear, belief in the importance of superiority over others, a determination to use any means for self-aggrandisement, and a destructive rage when thwarted.

Dr Torgensen, professor of psychology at Oslo University, has agreed that Breivik is a psychopath and he heightened Breivik's "delusions of grandeur and his belief that he was singled out to be a knight in the crusade against Islam". His photo and grandiose pose with weapons and medals and bogus uniform left $\mathrm{Dr}$ Torgensen in no doubt that Breivik is a psychopath with an extreme narcissism. Breivik's case confirms that psychopathy is not a simple disorder but rather a distinct pathological syndrome where so many symptoms are conscripted into maintenance and bolstering of the grandiose self at the syndromal level (Zepinic, 2018).

Unlike usual practice in case of insanity defence, in Brievik's case, the defence argued that he was mentally competent while committing the crime. His attorney argued that his actions were undertaken solely with his political motive in mind- "defending Norway against Islamic colonisation". Regardless how one feels about the motive, it was clear that the effect of finding Breivik not guilty would have been to discredit his actions as the work of a "madman". However, his approach could be misused in some totalitarian regimes, which prefer psychiatric hospitalisation for the political opponents rather than offering a response to their dissatisfaction. The temptation to use an imposed insanity defence to discredit opponent is real, and it constitutes another reason for caution in allowing a court to substitute its preference for the choice of the accused.

\section{Psychopaths and Terrorism}

It is undisputable that bombings of the World Trade Centre in New York City and the Federal building in Oklahoma City changed our perception of whether people at any stage of personality disorder can do such barbaric acts against innocent people. Yes, it is evident throughout the history that human beings are alone among all animal species who impose terror and mass murder in their own society. However, the terrorism and organised crimes against people raise the serious question about the psychopathic personalities of the terrorists, either as the executors or the planners.

Two terrorist acts stated above shocked the entire world, as before these events, it was inconceivable that any unresolved ethnic-nationalist conflicts, some individual's inner conflicts, or a deeply alienated individual could produce a level of violence resulting in the death and wounding of hundreds of civilians. Sadly, but since the terrorist attack on the World Trade Centre in New York City, terrorism has become endemic around the globe, creating general anxiety and fear for people's safety. Even worse, in many cases, violence and armed con- 
flicts have become a natural part of everyday life in many areas.

With a loss of real identity figure, people usually try to identify with those who have a power-the authority figure which might give some directions and meaning. Sadly, the role models often turn out to be terrorists and guerrillas who perpetrate much of the violence. In such circumstances, bonding with the powerful, charismatic figure, the terrorist, via the brutality of the terrorist act, shows his presumptive commitments towards social, political, cultural, psychological identification and liberation. Identifying with the terrorists is not merely thrilling, but logical for those whose sense of own self is discontinued or distorted. If some vulnerability has been shown during their childhood (domestic violence, negligence, broken relationships, etc.) it seems that violence is the logical thing to do for a hopeless adolescent. This indicates a general psychological transformation where personal identity derives from a series of the "fragments" and self-discontinuity (Zepinic, 2018) rather than the coherent social whole.

These new cultural and political identities often manifest the individual's conformation with the outer world as an unsafe and very dangerous place. However, it is important to say that the terrorism planners use terrorism as a methodology rather than ideology, using vulnerable individuals for their targeted goals. For psychopathic planners (leaders), terror is a strategy designed to instil general fear and provoke a government into reckless acts of the repression so that the individual (personal), rather than political, conflicts are in effect. Nevertheless, it is important that the organised violence be executed by individuals who are members of some group to sanction the act in the name of political goals.

However, they will not consider themselves as criminals but rather aggrieved individuals, revolutionaries, patriots, and "freedom fighters" for some rights. This is something typical for the psychopath defined by Hare (1970): lack of remorse of shame, failure to learn by the experience, grandiose sense of self-worth, callous/lack of empathy, lack of realistic and long-term goals, failure to accept responsibility for the own actions, absence of guilt, and criminal versatility.

The terrorists' psychopathy is based on the pathological stimulation that disturbs their socialisation. In many examples, it was evident that those with the inferior socialisation commit an organised violence. The evidence supports the view of the psychopath terrorist as an individual in a state of an aversive stimulus deprivation which compels him to perform the antisocial behaviour (terrorism), which raises his arousal to an acceptable level. In typical psychopath's absence of guilt, inability to form an intimate relationship, lack of the responsibility, specific loss of insight, and low anxiety, are due to his view of both the others and himself as the objects of manipulation. As a result, psychopaths fail to internalise social norms and values and act without consideration of inevitable effects and damages upon others.

Disinhibition of antisocial behaviour and creation of depersonalised state produce lack of integration and self-cohesion, making an individual uncertain, 
insecure, and vulnerable. Such individuals experience a loss of self-control, but needs of pathological control over the others in order to increase their deficient level of arousal. Due to his detachment and despair associated with a sense of contradiction and ambiguity in the norms and values, which impairs proper integration into society, the psychopath chooses an action by which he rejects social norms and methods, seeking acceptance by some group. Of course, the announced goals and identities are utterly unjustifiable, but the psychopath terrorist remains as an individual with his specific loss of insight.

Individual with this personality syndrome tends to take advantage of others, he is "out for number one", and has little investment in moral values. He tends to be deceitful, to lie or mislead, and to engage in unlawful (criminal) behaviour. He has little or no empathy at all, appears to experience no remorse for harm or injury caused to others, and may show reckless disregard for the rights and social norms, property, and safety of others. Terrorist tends to act impulsively, without regard for consequences. He/she seems unconcerned with consequences and appears to feel immune or invulnerable. He/she tends to be unreliable and irresponsible, and tries to manipulate others' emotions to get what he/she wants.

In social relations, the terrorist usually tends to be angry or hostile because of something, to seek power or influence over others who are servile or loyal, and to be critical of such individuals. Terrorist appears to gain pleasure or satisfaction by being aggressive or sadistic, and tends to be conflicted about authority, and is prone to get into power struggles. Terrorist blames others for his/her own failures or shortcomings and appears to believe that his/her problems have entirely been caused by external factors having little psychological insight into own motives and behaviour.

\section{Psychopathy and Political Crime}

"When someone kills a man, he is prosecuted for murder. When someone kills twenty people, he is declared insane. When someone is responsible for killing 200,000 people, he is invited to the UN for a peace negotiation"-joke from Sarajevo, 1994.

The political crime is perhaps the oldest of all crime-types-it has always existed, it exists now, and it will exist in the future. Although political crime is the oldest and most recurring criminal phenomenon it has been largely ignored by law, criminology, and sociology. The neglect of political crime by the criminologists and other scientists is the more surprising because of available data are quite extensive and there are no peculiar difficulties in attempting to analyse it (Shafer, 1971). Perhaps one of the reasons for the long-standing inability to find an answer for political crimes is that lawyers are too close to the problem-makers and other scientist too distant from, and both are reluctant to bring it into the law domains.

This paper is focused to the criminal man (psychopath) not to the criminal act, what is the interest of law. Political leaders are usually characterised by their 
passion and high degree of affectivity, so that is unusual and strained circumstances, they develop a passion that leads to the violent crimes. However, as successful psychopaths, the leaders are moved by psychopathic deviation, justification for avoiding constructive work, and produce the criminality and "immorality of political maxima". This moral depravity leads psychopathic leader to the human rights violation (torture, extrajudicial arrest and imprisonment), or violation of international law.

The most difficult to connect psychopathy with the political crimes is that those who have committed crime during their political power are very rare, or never, examined regarding their psychopathic personality. In practice, it is common that some experts (psychiatrists, psychologists, sociologists) are required to make a comment (opinion) on a possible link between the psychopathy and the personality of a political leader accused of torture and crimes against humanity. Even all the images and commentary on every aspect of the hostilities and the politics generating them is not enough to form an "expert opinion", which represents nothing other than long-distance diagnosis of successful psychopath. Such "expert report" can be a form of glorified gossip, lent credence not by the facts but merely by the expert's credentials.

For example, Dr Jerrold Post, professor of psychology and politics at George Washington University, ("Expert Differ on Dissenting Leaders' Psyches from Afar"-The New York Times, 19 January 1991) in testimony to the US Senate, claimed that the Iraqi President Saddam Hussein was suffering from "malignant narcissism, a severe personality disorder that leaves him grandiose, paranoid, and ruthless". CNN on 13 February 1991 described Hussein as "sociopathic" based on no any evidence, but this was enough for lay people to make a judgment about his psychopathic behaviour.

Nevertheless, the psychological profile and the seriousness of Hussein's psychopathy made predictions about his future actions stating before 15 January 1991, the deadline that former US President Bush gave Hussein an order for withdrawal from occupied Kuwait. An interesting twist happened regarding this situation, as on 7 February 1991, the Canadian Broadcasting Corporation news program stated: "Bush wants to kill all Arabs. He is a psychopath". When the diagnosis of the person of interest has profound implications for the general public, we must make certain whether it is an accurate opinion within the acceptable limits (Zepinic, 2018).

The destructive potential of diagnostic labels in court takes reality only if properly assessed by the expert. However, in most cases, science is shortened with such evidence (such in Hussein's and Bush's cases), and research is based mostly on ordinary criminal, not political psychopaths. The court sentencing on political figures and dictators revealed that 1) they deliberately sought the oppression of their opponents; 2) there was probability that the accused would commit criminal acts of violence, torture, or murder in the future; and 3) there was no reasonable "provocation" for the accused's conduct. This in turn takes us 
to the proposition that if one is going to do something wicked then the penalty is likely to be lighter if one has been unprincipled all one's life, and the crime committed is repetitive and monstrous.

Political psychopaths have usually been "successful" in their political careers until they are prosecuted for the crimes against humanity, or crimes committed against own people (nation). From the Nurnberg process against the Nazi leaders until modern criminal proceedings against political leaders (Cambodia, Ruanda, former Yugoslavia, Congo, Sierra Leone, ...), none of the accused has ever accepted any of wrongdoing while in power. This is quite expected behaviour (defence) from them, as psychopaths do not feel they have psychological or emotional problems, and they see no reason to change their behaviour to conform to societal standards with which they do not agree (Shafer, 1971). At least, two the most notoriously destructive men, Joseph Stalin and Adolf Hitler, had never accepted of doing anything wrong.

Researchers describe bad leaders as toxic, abusive, tyrannical, and destructive, and a common behaviour is to ridicule and degrade employees. Their relationships with others are characterised by lying, deceptiveness, blaming others for their mistakes, harassment, and verbal or physical aggression. In essence, such individuals exhibit behaviour and personality that can be seen in psychopaths, and psychopathy may well be one underlying factor explaining bad leadership behaviour (Mathieu et al., 2015). Hare (1993) was of opinion that the most obvious expressions of psychopathy involve flagrant criminal violation of society's rules. Using their charm and chameleon-like abilities, psychopaths cut a wide swath through society, leaving a wake of ruined lives behind them.

The personality traits approach to understanding bad leadership has garnered attention through the history of human beings. However, this phenomenon has been shown differently depending on development and governing of the society (nation), cultural issues, specific circumstances, and many other factors that the leader used to "justify" his leadership rejecting any wrongdoing. McCrae \& Allik (2002) developed a five-factor model of personality traits (domains) that have been shown to exist across all cultures: 1) extroversion (social, gregarious, assertive, active, exciting, cheerful); 2) agreeableness (trusting, honest, complaint, modest, tender-minded); 3) conscientiousness (competent, orderly, dutiful, achievement oriented, disciplined, plans ahead); 4) emotional stability (calm, friendly, happy, not self-conscious, further thinking, thick skinned/not vulnerable); and 5) openness to experience (imaginative, artistic, emotionally deep, experimental, curious, and diverse).

Hare \& Newman (2009), using the $P L C$ - $R$ to investigate psychopathy, underpinned by the correlates factors or dimensions, labelled it as follows: interpersonal (manipulativeness, glibness, superficial charm, grandiose sense of self-worth, pathological lying), affective (lack of remorse or guilt, shallow affect, callous/lack of the empathy, failure to accept responsibility for their actions), lifestyle (need for stimulation/proneness to boredom, parasitic lifestyle, lack of 
the realistic long-term goals, impulsivity, irresponsibility), and antisocial (poor behaviour controls, early behavioural problems, juvenile delinquency, revocation of conditional release).

Babiak, et al. (2010) found that psychopathy-particularly its interpersonal components-was positively associated with in-house company ratings of charisma and presentation style (creativity, strategic thinking, and communications skills) and negatively associated with ratings of responsibility and performance (being a team leader, leadership and management skills, and/or overall accomplishment). They found the PLC-R threshold for the psychopathy among the sample of leaders was much higher than the prevalence estimated for the general population. The authors concluded that the ability to charm, manipulate, and deceive others allowed the psychopathic leaders to achieve apparent success in their careers despite negative performance ratings and behaviours potentially harmful to the company, and/or others.

Thus, Babiak et al. (2010) found that the leaders (political or managerial) could have their psychopathy and be very harmful for their followers and/or society at large. In his article highlighting the personality of Dr Karadzic the most wanted war criminal in Europe since World War II, Dr Kaplan (2003) professor of Psychiatry at University of Wollongong, Australia, analysed Dr Karadzic's profile. This Bosnian psychiatrist, who was accused of the genocide and crimes against humanity in former Yugoslavia, was arrested and prosecuted in ICTY. Dr Kaplan stated that Dr Karadzic had a grandiose self-image, reckless and profligate nature, boundless opportunism, emotionless, and grotesque capacity for self-deception. As the nationalist and genocide leader, he displayed an extraordinary degree of reckless opportunism, in which the instincts of an extreme gambler were unchallenged by any restrain or fear of the consequences.

Dr Kaplan (2003) further stated that Dr Karadzic presented to a psychotherapy conference in 1987 a paper analysing a poem about bizarre bodily mutilation, and wrote poems called "Let's Go Down to the Town and Kill Some Scum" and "Sarajevo", speaking of his city of living burning in a "blood-soaked tide". In general, Dr Karadzic's poetry reveals the writer's obsession with blood and violence.

According to Dr Kaplan, Dr Karadzic's colleagues at the Psychiatric Clinic in Sarajevo, were aware of his grandiosity and unrealistic plans; the frequent assertion that he would become a famous psychiatrist or poet were regarded with scepticism by others. His best friend described him as "a psychopath, man without a core" and the mechanism for the falsification of reality was his most distinctive quality. Dr Kaplan (2003) further stated that Dr Karadzic had a grandiose and romantic vision of himself, and his ambivalence about finding role to express his abilities was pervasive. Nevertheless, his grandiose self-image, reckless and profligate nature, the boundless opportunism, and grotesque capacity for the self-deception led his genocide career to its apogee.

Many powerful historical figures (Hitler, Mussolini, Stalin, Pol Pot, etc.) had 
shown active or passive sadomasochistic or necrophilia strivings that caused nihilism, aggressiveness, and destructiveness towards targeted objects. Fromm (1974) was of the opinion that such personality structure is rooted in the unbearableness of the individual's powerlessness and isolation- "I can escape the feeling of my own powerlessness in comparison with the world outside myself by destroying it'. This could be the psychopath leader's anatomy of his hostile aggressiveness-a tendency of social dominance, threatening behaviour, and hostility. As it was evident in history, such personality traits may cause a transient change in behaviour within an individual or be characteristic traits of an individual.

Aggressiveness towards particular individuals or groups, or even the entire nations, is a desperate attempt to hide the powerlessness, which should be replaced by domination over the others. This aggressive attitude is often seen in the absence of any outside threat. In many other situations, powerlessness is not psychopath's conscious process, as well as aggressiveness toward others. In fact, the psychopath targets his own weakness to be replaced by desired, but never achieved, power and authority.

However, although it is not conscious, aggressiveness (destructiveness) is rationalised in various ways. In fact, there is virtually nothing that is not used as a rationalisation for the psychopath's destructiveness. Love, duty, conscience, and patriotism have been and are being used as rationalisation to destroy others or oneself (Zepinic, 2018). This could be challenged in two different ways: 1) tendencies that result from a specific situation, or 2) the isolated and powerless individual is blocked in realising his sensuous, emotional, and intellectual potentialities. The kind of aggression is the natural and necessary concomitant of one's affirmation of life.

Aggressiveness exercised by a person in power, but with personality powerlessness, is not his reactive or defensive hostility-it is a condition that is a constantly lingering tendency within a person, which waits only for an opportunity to be expressed. If there is no objective reason for expressing aggressiveness, it is an evident sickness of personality, although the psychopath himself will usually build up some sort of rationalisation. In most cases, the destructive impulses are rationalised in such way that, at least, other people or whole social group or nation share in the rationalisation, and thus it appears to be realistic to the members of such "unique" group. However, the objects of irrational aggressiveness and the particular reasons for their being chosen are options of only secondary importance to the aggressor-the inner tendencies are the passion within the person. If, for any reason, the group or individual cannot become the object of the leader's aggressiveness, then his own self easily becomes the object.

We have assumed that the aggressiveness is an escape from unbearable powerlessness, since it targets the removal, or replacement, of all objects with which the individual has to compare and deal himself. However, this explanation is not always sufficient, as one's aggressiveness could also be a fear and the 
thwarting of life. Concerning fear, it is evident that the threat against or targeting of the individual's vital (emotional or intellectual) interests create fear (anxiety), and aggressiveness is a common reaction to such fear. The threat can be circumscribed in a particular situation or particular person(s) and, in such situation, aggressiveness is aroused towards these persons. Fear can also be a constant, although usually not conscious, with an equally constant feeling of being threatened by the world outside Fromm (1974). In fact, the real threat is inside the individual, characterised by his inner conflict drives that he cannot control (Zepinic, 2017). This kind of constant psychological equilibrium results in the individual's isolation and powerlessness-the main source of the reservoir for the aggressiveness that had developed within him.

The isolated and powerless individual is blocked in, realising his sensuous, emotional, and intellectual potentialities-a situation called the thwarting of the life. He lacks the inner security, mostly overwhelmed by the inner conflict drives and spontaneity that are the conditions for potential aggressiveness. This inner blockage is increased by cultural or political taboos on pleasure and happiness, which is expected to be brought by the leader. However, his power is almost vanished, and inner blockage has remined strong despite the power given to the individual by his leadership. The individual is then brought into a condition of self-preservation, what Freud (Freud, 1920) identified as a death-instinct, whose aim is the destruction of life. Fromm (1974) stated that destructiveness is an outcome of unlived life; a condition that makes for suppression of life and hostile tendencies-either against others or oneself-caused by the suppression of the individual's expansiveness.

As stated earlier, despite his constant charm, the psychopath is an authoritarian character with the presence of a chronic and pervasive disposition to disregard and violate the rights of others. His personality is characterised by repeated violations and exploitation of the others, deceitfulness, impulsivity, aggressiveness, recklessness disregard for the safety of the self or others, irresponsibility, and lack of guilt, remorse, and empathy. In general, the psychopath is a person who is mentally unbalanced-a disintegrated self. However, the psychopaths are well satisfied with themselves and with their inner landscape-they see nothing wrong with themselves, experience little or no personal distress, and find their behaviour rational, rewarding, and satisfying.

Psychopathic leaders never look back with the regrets or forward with concerns; they perceive themselves as superior beings in a hostile, dog-eat-dog world in which others are weak opponents that deserve nothing but punishment. Psychopaths feel it is legitimate to manipulate and deceive others in order to obtain their "rights", and their actions are planned to outmanoeuvre the malevolence they see in others. Further, psychopaths are not "fragile" individuals, and what they think and do are extensions of their rock-solid personality structure that is extremely resistant to an outside influence, even the legal system. Psychopaths dominate over the individuals and groups, imposing their own views 
and interpretations on the other members.

It is common that ideas by a leader in power are consciously accepted by certain groups, on account of the peculiarities of their social character, are not really touched by them. In cases where ideas produce a social wrong but people fail to act accordingly, the leader will see ideals as a stock of the conscious group responsibility and convictions. Responsibility is usually related to aggressive behaviour toward others, which presupposes the existence of frustration, reasonable or not, with the attacked group. However, when talking about the political leaders' psychopathic behaviour, the terms "insanity" and "mental sickness" are unpopular, and the word "moral depravity" is accepted without defining it. Thus, the "moral defectives" does refer neither the deficiency of mind or brain, but of morality. Psychopathy for leaders is no a quantitative description, but a firm category, although the psychopath and the moral defective are indeed the same person (Ellard, 1989).

Individuals who have imposed aggressiveness upon others in order to achieve own goals exercise lack of empathy and tend to be callous, cynical, and contemptuous of the feelings, and suffering of others. They may show an inflated and arrogant self-appraisal and can be excessively opinionated and self-assured. They may display superficial charm and can be quite valuable and verbally facile, but using highly sophisticated verbal terms in order to impress followers. Lack of empathy, inflated self-appraisal, and callousness are features that have been commonly included in the traditional concept of psychopathy.

The social leaders with these characteristics do not feel responsible for what happens to others, always defending their own goals and blaming others as incapable of following their genius ideas. They show a pattern of their unstable and intense interpersonal relationships, characterised by extremes of idealisation and devaluation, unstable self-image or sense of self. They may experience dysphoria, including complaints of tension, somatic symptoms disorders, gambling disorders, disorders of impulse control, and depressed mood. Their dysphoric mood is often disrupted by periods of intense and inappropriate anger, panic, or despair, rarely revealed by periods of well-being. They usually cannot control their anger and may display sarcasm, enduring bitterness, and verbal outbursts (Zepinic, 2017).

Psychopathic leaders show some characteristics of borderline personality they make frantic efforts to avoid reality or the loss of the external structure, and can do profound changes in their self-image, affection, and behaviour. These individuals are sensitive and fearful of being rejected and abandoned, and if they feel like that, they will react with inappropriate anger, even when face with reality. They may feel that the abandonment of their plans implies that their personality is perceived to be faulty, and they need others to glorify them. They feel satisfaction when being called "president", "boss", "chief", etc., although their ideas or actions have been disastrous. Such psychopaths usually have unstable and intense relationships, and they quickly switch from idealising other people 
to devaluating them, feeling that other people do not give or do enough, or not "their" enough. These individuals can emphasise and nurture other people, but only with the expectations that others will be "there" in return to meet their needs on demand.

Their grandiose self-image (importance) needs admiration by others, who should glorify the psychopath's accomplishments. The followers cannot display any closeness to the psychopath's achievements and, due to their grandiosity, the psychopaths are often preoccupied with fantasies of their unlimited success (having "Napoleon syndrome"), power, or brilliance, and feel that admiration of close followers should be their privilege. The psychopath expects that everyone with whom he associates will recognise and respect his uniqueness and qualities beyond those of ordinary people. His self-esteem and credentials are enhanced by the idealised values that he assigns to those with whom he associates. The psychopathic leader expects his arrival to be greeted with great fanfare, with a "reasonable" expectation of special favourable treatment by his associates. This sense of entitlement, combined with a lack of sensitivity to the wants and needs of others, in addition to his grandiosity, may result in the consciously imposed destruction of others or of non-followers (Zepinic, 2003).

\section{Discussion}

Over decades, science (psychiatry, psychology, law, criminology, etc.) overtook attempt to explain "inexplicable" behaviour and to take the weight in decision about an individual's (in)capacity, responsibility, competence, and dangerousness. A consistent theme running through the clinical findings that the DSM criterion sets for personality disorders are too narrow. Current DSM-5 limits the number of diagnostic criterion, but it is clinically and psychometrically impossible to describe personality syndromes in their complexity. This inevitably has placed the mental health professionals into the criminal justice proceedings: to being able to scientifically validate the accused's personality, which might reinforce the legal approach towards mentally ill individuals. However, even in modern time some jurists traditionally regard mental disorders as disturbing phenomena that are beyond their comprehension-they have made little effort to comprehend psychodynamic theory or diagnostic terminology.

It is beyond any doubt that psychopaths are mentally-ill individuals with, even within expert scientific circles, a poor understanding and uncertainty in regards to psychopathy. Many people are shocked when we tell them that psychopaths are found in the majority of workplaces (Gao \& Raine, 2010; Babiak \& Hare, 2006). It is common that the psychopath is hidden by virtue of his superior manipulative abilities and sheer intelligence. This successful psychopath is hard to flush out and even harder to contain if he is allowed to flourish. However, it is a question how exactly we can identify this chameleon when he is well adept at hiding behind a false facade and so supremely skilful at playing the system and invariably winning. 
The DSM-5 criterion sets for the personality disorders do not capture the complexity of personality syndromes evident in the psychopaths (multiple domains of the pathological functioning including cognition, affectivity, interpersonal relations, and the impulse regulation). Certain traits play central roles in more than one personality disorder (e.g., lack of empathy is characteristic of both narcissistic and antisocial personality disorder, hostility is characteristic of paranoid, antisocial, borderline, and narcissistic personality disorder). Such traits require multifaceted criteria to define complex comorbidity of one's personality. Expanding the size of the criterion sets and impose a syndromal, not a simple personality disorder, would 1) help bridge the gap between science and practice by making DSM criterion sets more faithful to clinical reality; 2) make the personality disorder more faithful to the theoretical construct of psychopathy; and 3) reduce comorbidity among personality disorders by making diagnostic category more distinct.

Needless to say, it is necessary to make a distinction between typical criminal psychopath and successful psychopath in the workplace and community. The criminal psychopath displays no sense of responsibility with regards to his job but appears legitimate within society to cover his illicit activities. On the other hand, the successful psychopaths are very intelligent and methodological and can be extremely effective at what they do-they are not engaged in physically destructive or criminal behaviour. Unlike criminal psychopath, the successful psychopaths usually stay within the same company for a prolonged period. It is common that, due to long-serving and outstanding abilities within their profession, they are promoted to a higher position.

For the clinical point of view, it is important to emphasise aspects of inner experience or mental life that centrally defines the successful psychopath's personality. For example, the data strongly indicate that externalisation and projection, hostility, lack of empathy, lack of remorse, lack of insight, the self-importance, and power-seeking are defining features of the successful psychopaths (Hare, 1970; Gao \& Raine, 2010; Hare \& Newman, 2009).

The psychopath is unwilling to face the realities of the life, and he us usually destructive, although he could follow some rules by reason of his makeup to avoid punishment. In general, the psychopaths are ill-equipped individuals to meet the demands of the environment, with a lack of responsiveness to the social demands of honesty, truthfulness, decency, and consideration for others. The defects and its consequences incapacitate the psychopath from settling down to do permanently ordinary activities. The individual is emotionally unstable, cannot be dependent upon, and often acts on impulses with poor judgment and lack of decision-making ability. Psychopaths are frequently led into unwise or risky activities, the consequences of which they may be able to realise intellectually, but not properly evaluate.

The definition of mental disorders in DSM-5 (APA, 2013) is a quite controversial and puzzling in regards to the definition of psychopathy: can the suc- 
cessful psychopath satisfy the criteria for a mental disorder? On the other hand, it is quite questionable and unacceptable that those who evidently were psychopaths (Hitler, Mussolini, Himmler, Stalin, Pol Pot, etc.) cannot satisfy the criteria for a mental disorder. A further puzzle in regards to psychopathy is the fact that this syndromal condition is not a simple diagnosis contained in the DSM-5 or ICD-11, and, according to the diagnostic criteria, the diagnosis of a mental disorder should have clinical utility: it should help clinicians to determine the prognosis, treatment plans (even some medication), and potential treatment outcomes for their patients.

This paper is primarily exploratory, aimed at identifying constructs and variables of serial killers' psychopathy and political crimes for a further investigation. This area of one's psychopathology is of greater-than-average clinical and public interest, but with limited research data.

\section{References}

American Psychiatric Association APA (2013). Diagnostic and Statistical Manual of Mental Disorders (DSM-5). Washington DC: APA. https://doi.org/10.1176/appi.books.9780890425596

Appelbaum, P. S. (2013). Imposed Insanity Defences and Political Crimes. Psychiatric Services, 1, 4-6. https://doi.org/10.1176/appi.ps.640102

Babiak, P., \& Hare, R. D. (2006). Snakes in Suit: When Psychopath Goes to Work. New York, NY: HarperCollins.

Babiak, P., Newman, C., \& Hare, R. D. (2010). Corporate Psychopathy: Talking the Walk. Behavioural Science and Law, 28, 174-193. https://doi.org/10.1002/bsl.925

Blair, R. J. R. (2006). Psychopathy. Emotion and the Brain. New York, NY: Willey-Blackwell.

Cleckley, H. C. (1982). The Mask of Sanity (9th ed.). St. Louis, MO: Mosby Medical Library.

DeLisi, M. (2009). Psychopathy Is the United Theory of Crime. Youth Violence and Juvenile Justice, 3, 256-273. https://doi.org/10.1177/1541204009333834

Ellard, J. (1989). Some Rules for Killing People. London: Angus \& Robertson.

Fromm, E. (1974). The Anatomy of Human Destructiveness. London: Jonathan Cape.

Freud, S. (1920). Beyond the Pleasure Principle (Standard Edition 19). Vienna, London: Hogarth Press.

Gao, Y., \& Raine, A. (2010). Successful and Unsuccessful Psychopaths: A Neurobiological Model. Behavioural Science and Law, 28, 194-210. https://doi.org/10.1002/bsl.924

Glover, E. (1960). The Roots of Crime. London: Imago Publishing.

Hare, R. D. (1970). Psychopathy: Theory and Research. New York, NY: John Willey \& Sons.

Hare, R. D. (1993). Without Conscience: The Disturbing World of the Psychopaths among Us. New York, NY: The Guilford Press.

Hare, R. D., \& Newman, C. (2009). Psychopathy: Assessment and Forensic Implications. Canadian Journal of Psychiatry, 4, 217-246.

https://doi.org/10.1177/070674370905401202

Iria, C., \& Barbosa, F. (2009). Perception of Facial Expression of Fear: Comparative Re- 
search with Criminal and Noncriminal Psychopaths. Journal of Forensic Psychiatry and Psychology, 20, 66-73. https://doi.org/10.1080/14789940802214218

Jenkins, R. L. (1960). The Psychopathic or Antisocial Personality. Journal of Nervous and Mental Disease, 131, 318-334. https://doi.org/10.1097/00005053-196010000-00005

Kaplan, R. (2003). Dr Radovan Karadzic: Psychiatrists, Poet, Soccer Coach and Genocide Leader. Australasian Psychiatry, 11, 74-78. https://doi.org/10.1046/j.1440-1665.2003.00519.x

Kreamer, G. W., Lord, W. D., \& Heilburn, K. (2002). Comparing Single and Serial Homicide Offenders. Behavioural Science and Law, 22, 325-343. https://doi.org/10.1002/bsl.581

Mathieu, C., Newman, C., Babiak, P., \& Hare, R. D. (2015). Corporate Psychopathy and Full-Range Leadership Model. Assessment, 22, 267-278. https://doi.org/10.1177/1073191114545490

McCrae, R. R., \& Alik, J. (2002). The Five-Factor Model of Personality across Cultures. New York, NY: Kluwer Academic. https://doi.org/10.1007/978-1-4615-0763-5

Patrick, C. J. (2006). Handbook of Psychopathy. New York, NY: The Guilford Press.

Raine, A., Ischicawa, S. S., Arce, E. et al. (2004). Hippocampal Structural Asymmetry in Unsuccessful Psychopaths. Biological Psychiatry, 55, 185-191. https://doi.org/10.1016/S0006-3223(03)00727-3

Shafer, S. (1971). The Concept of the Political Criminal. The Journal of Criminal Law, Criminology and Police Science, 3, 380-387. https://doi.org/10.2307/1142177

Walters, G. D. (2004). The Troubles with Psychopathy as a General Theory of Crime. International Journal of Offender Therapy and Comparative Criminology, 48, 1-16. https://doi.org/10.1177/0306624X03259472

Zepinic, V. (2003). Political Leaders or Political Criminals: An Example from Former Yugoslavia. Psychology Bulletin, 6, 15-31.

Zepinic, V. (2017). Posttraumatic Stress Disorder in Courtroom: Insanity Defence. American Journal of Applied Psychology, 6, 22-30. https://doi.org/10.11648/j.ajap.20170602.12

Zepinic, V. (2018). Psychopathy: Guilty Mind or Guilty Brain. London: Austin Macauley Publishers. 